\title{
Habitat selection by marine larvae in changing chemical environments
}

\author{
D. Lecchini ${ }^{\mathrm{a}, \mathrm{b}, *}$, D.L. Dixson ${ }^{\mathrm{c}}$, G. Lecellier ${ }^{\mathrm{b}, \mathrm{d}}$, N. Roux ${ }^{\mathrm{a}, \mathrm{e}}$, B. Frédérich $^{\mathrm{f}}$, M. Besson $^{\mathrm{a}, \mathrm{g}}$, Y. Tanaka $^{\mathrm{h}}$, \\ B. Banaigs ${ }^{\text {a }}$, Y. Nakamura ${ }^{\mathrm{i}}$ \\ a EPHE, PSL Research University, UPVD-CNRS, USR3278 CRIOBE, F-66360 Perpignan, France \\ b Laboratoire d'Excellence CORAIL, Moorea, French Polynesia \\ c School Marine Science and Policy, University of Delaware, Newark, USA \\ ${ }^{\mathrm{d}}$ University of Versailles-Saint, Versailles, France \\ e Equipe Biologie Intégrative de la Métamorphose BIOM UMR7232 CNRS-UPMC Observatoire Océanologique de Banyuls sur mer, Banyuls sur mer, France \\ ${ }^{\mathrm{f}}$ Laboratoire de Morphologie Fonctionnelle et Evolutive, AFFISH Research Center, Liege, Belgium \\ g Molecular Zoology Team, Institut de Génomique Fonctionnelle de Lyon, Université Lyon 1, CNRS UMR 5242, Ecole Normale Supérieure de Lyon, Lyon, France \\ ${ }^{\text {h }}$ Sesoko Station, Tropical Biosphere Research Center, University of the Ryukyus, Sesoko, Japan

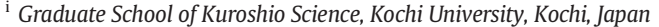

\section{A R T I C L E I N F O}

\section{Article history:}

Received 3 February 2016

Received in revised form 25 August 2016

Accepted 30 August 2016

Available online 3 September 2016

\section{Keywords:}

Coral reef

Larval recruitment

Acidification

Pesticides

Red soil pollution

\begin{abstract}
A B S T R A C T
The replenishment and persistence of marine species is contingent on dispersing larvae locating suitable habitat and surviving to a reproductive stage. Pelagic larvae rely on environmental cues to make behavioural decisions with chemical information being important for habitat selection at settlement. We explored the sensory world of crustaceans and fishes focusing on the impact anthropogenic alterations (ocean acidification, red soil, pesticide) have on conspecific chemical signals used by larvae for habitat selection. Crustacean (Stenopus hispidus) and fish (Chromis viridis) larvae recognized their conspecifics via chemical signals under control conditions. In the presence of acidified water, red soil or pesticide, the ability of larvae to chemically recognize conspecific cues was altered. Our study highlights that recruitment potential on coral reefs may decrease due to anthropogenic stressors. If so, populations of fishes and crustaceans will continue their rapid decline; larval recruitment will not replace and sustain the adult populations on degraded reefs.
\end{abstract}

(c) 2016 Elsevier Ltd. All rights reserved.

\section{Introduction}

Coral reefs are home to approximately $25 \%$ of the ocean's biodiversity while only accounting for $0.02 \%$ of the ocean's surface area (Spalding et al., 2001). Due to the economic and environmental importance, unique assemblage of organisms, and high species diversity found on coral reefs, protective measures are critical (Chin et al., 2011; de Groot et al. 2012). Beginning in the early 1990's, questions have been raised concerning the resilience of coral reefs to global changes (Grigg and Dollar, 1990). Today, it is estimated that $20 \%$ of coral reefs have been destroyed, 25\% are under great immediate threat, and a further $25 \%$ will be under threat by 2050 (Chin et al., 2011). Several studies have shown that coral reefs exposed to a disturbance event often exhibit a decline in adult populations. This decline leads to accelerated rates of extirpation compared to "non-degraded" habitats (Hughes et al., 2003; Munday et al., 2009). For example, the decline in adult populations of coral reef fishes on degraded reefs in Papua New Guinea was a reflection of larval recruitment failure rather than adult mortality.

\footnotetext{
* Corresponding author at: EPHE, PSL Research University, UPVD-CNRS, USR3278 CRIOBE, F-66360 Perpignan, France.

E-mail address: lecchini@univ-perp.fr (D. Lecchini).
}

Results suggest the "rescue" effect of recruitment may be ineffective in degraded habitats (Jones et al. 2004). Unfortunately, the mechanisms that determine how pelagic larvae respond to different environmental stressors and the role anthropogenic induced change plays during settlement site selection by recruiting organisms remains poorly understood (Hanski and Gilpin, 1997; Lecchini et al., 2013; Dixson et al., 2014).

Most species of coral reef fishes and crustaceans have stage-structured life histories: a relatively sedentary benthic stage (juveniles and adults) produces highly dispersive pelagic larvae (Kingsford et al., 2002). The transition from the pelagic environment to a benthic reef (i.e., recruitment process) represents a key period in the ontogeny of marine organisms (Lecchini, 2005). At recruitment, fish and crustacean larvae are subjected to strong selective pressure to choose a suitable reef habitat that will promote post-recruitment survival and growth of individuals (Doherty, 2002). Up to $90 \%$ of fish larvae may be removed by predation during the first week post-recruitment if suitable habitat was not selected (Doherty et al., 2004). Thus, many fish and crustacean species show high selectivity in suitable reef habitat; basing decisions on the presence of specific substrates and/or conspecifics, as well as the absence of predators and/or competitors (Kingsford et al., 2002; Lecchini et al., 2010; Barth et al., 2015). Chemical cues are often used 
by fish and crustacean larvae to locate suitable reefs (Leis et al., 2011; Lecchini et al., 2013; Dixson et al., 2014), to identify conspecifics (Dixson et al., 2011), and to avoid predators (Dixson et al., 2012). For example, settling fish larvae are capable of olfactory discrimination among reefs, preferring the water-borne odors of their home reefs compared to neighboring reef habitats (Gerlarch et al., 2007). The understanding of how animals make decisions is a fundamental question in behavioural ecology (Feely et al., 2009; Barth et al., 2015). While evidence is mounting that larval organisms are active participants in the process of dispersal and recruitment (Lecchini et al., 2010), the sensory and behavioural mechanisms by which larvae disperse and return to appropriate habitat remain unknown. Understanding the recruitment process is especially important in the context of global reef decline due to natural and/or anthropogenic stressors (Munday et al., 2009; Lecchini et al., 2013; Dixson et al., 2014).

We investigated the behavioural response towards conspecific chemical stimuli by fish and crustacean larvae used in habitat selection during recruitment at two reef locations (Moorea Island, French Polynesia; Sesoko Island, Ryukyu Archipelagos, Japan). Research was conducted in the context of anthropogenic-induced change, specifically focusing on 1) ocean acidification, 2) red soil pollution and 3) pesticide pollution.

Since the beginning of the industrial revolution, atmospheric concentrations of carbon dioxide $\left(\mathrm{CO}_{2}\right)$ have risen dramatically. As atmospheric $\mathrm{CO}_{2}$ passively diffuses into the ocean's surface waters, seawater $\mathrm{pH}$ decreases, and in turn increasing water acidity (Feely et al. 2009). Several studies have shown that changes to seawater chemistry are predicted to impact the health and function of fishes (Munday et al., 2012; Leduc et al., 2013). We investigated how acidified seawater ( 700 and $1000 \mathrm{ppm}$ ) could alter the chemical cues of conspecifics available to fish and crustacean larvae.

Turbidity is one of the biggest sources of habitat degradation. The elevated amount of sediment suspended in the water column is generated by increased urbanisation and agricultural development run-off (Fabricius, 2005). We investigated the effects of red soil pollution (50 and $200 \mathrm{mg} / \mathrm{L}$ of red soil in clear or turbid water) on the chemical abilities of fish and crustaceans to recognize their conspecifics. The term "red soil" refers to a laterite soil prominent in Ryukyu Islands, Japan (Omija, 2004). The geographic features and rainfall patterns combined with surges in land development since the 1970s on Ryukyu Islands has resulted in the periodic erosive run-off and re-suspension of red soil. The increase in red soil runoff pollutes the surrounding coral reefs with high levels of silt and turbidity (Omija, 2004; O'Connor et al., 2016).

In contrast to the large numbers of studies testing the influence of pesticides on food and human health, few studies have explored its influence on reef biodiversity (Fabricius et al., 2005; Botte et al., 2012). In French Polynesia, Roche et al. (2011) illustrated the contamination of marine organisms (fish, green algae, mollusk, coral and holothurian) by several herbicides (chloroacetamide and triazine derivatives) and several insecticides (organophosphates and organochlorines). We examined the effect of the organophosphorus pesticide ( 1 and $100 \mu \mathrm{g} / \mathrm{L}$ of chlorpyrifos) on the chemical abilities of marine larvae to detect conspecific cues.

We hypothesized that conspecifics emit chemical cues that larvae are able to recognize in un-polluted seawater. However in the presence of anthropogenic pollution, the ability to chemically recognize conspecifics will be altered. Thus, if the recruitment potential of coral reefs has decreased due to these anthropogenic stressors (i.e. larvae unable to detect important chemical cues in polluted environment), the populations of fishes and crustaceans will continue to rapidly decline, as larval recruitment will not sustain adult populations on degraded ecosystems.

\section{Materials and methods}

\subsection{Sampling locations and target species}

Habitat naïve larval fish (Chromis viridis) and crustaceans (Stenopus hispidus) were collected just before settlement using light traps
(Nakamura et al., 2009a,b) set $300 \mathrm{~m}$ off of the fringing reefs on the south-east side of Sesoko Island $\left(26^{\circ} 38^{\prime} 08.94^{\prime \prime} \mathrm{N}, 127^{\circ} 51^{\prime} 55.04^{\prime \prime} \mathrm{E}\right)$. The acidification and red soil experiments were conducted at the Sesoko research station in August 2012. To conduct the pesticide experiment, habitat naive larvae were collected just before settlement using crest nets (Lecchini et al. 2004, 2006; Lo-Yat et al., 2011) set off the west coast of Moorea Island $\left(17^{\circ} 30^{\prime} 58.85^{\prime \prime}\right.$ S, $\left.149^{\circ} 55^{\prime} 26.77^{\prime \prime} \mathrm{W}\right)$ in MarchApril 2013. The capture of $S$. hispidus was low, therefore the pesticide experiment focused on $C$. viridis. All collected larvae were transferred and maintained in habitat free individual aquaria $(0.3 \times 0.3 \times 0.2 \mathrm{~m}$; water temperature: $26-27^{\circ} \mathrm{C}$ ) supplied with flow-through ocean seawater. Laboratory experiments were performed within $24 \mathrm{~h}$ of larval capture (Dixson et al., 2011; Lecchini et al., 2013). Conspecifics and heterospecifics, used as cues transmitters, were $C$. viridis and S. hispidus larvae reared in aquaria for 7 days post capture. C. viridis was used as the heterospecific cue for $S$. hispidus and vice versa. This was done to represent a post-settled juvenile stage. Larvae, conspecifics and heterospecifics were fed three times per day (live Artemia sp. Nauplii C. viridis and dead fish - S. hispidus).

\subsection{Behavioural experiments in choice flume}

A two-channel choice flume described in Gerlach et al. (2007) was used to test larval preferences between olfactory cues in present day and acidified seawater conditions (Exp. 1), water treated with or without red soil (Exp. 2), and pesticides (Exp. 3). Briefly, a flow rate of $100 \mathrm{~mL} / \mathrm{min}$ was maintained using flow meters. The low flow allowed larvae to swim without struggle against the current, ensuring movement patterns were a result of cue preference (Leis et al., 2011). Dye tests were conducted to confirm laminar flow within the chamber without eddies or areas of water mixing.

A larva was placed in the center of the downstream end of the flume during a 2 min habituation period. During this time the larva could explore the chamber and swim between the two parallel flowing water sources. Individuals that did not actively swim or explore both sides of the chamber during the habituation period were discarded $(<2 \%$ of fish and $<6 \%$ of crustacean). After the habituation period, the position of the larva, in either the right or left water channel, was recorded at five-second intervals for a two-minute test period. The water sources entering the chamber were then switched, with a one-minute rest period allocated to ensure the flushing of both channels (verified by dye tests). This was done to control for any side preferences individuals may display. After water sources were switched, another two-minute habituation period was given, followed by a second two-minute test period.

Preliminary experiments were conducted to 1 ) ensure no unanticipated biases existed for the two channel choice chamber;, 2) the use of chemical cues in the recognition of conspecific and heterospecific cues; and 3) to ensure repeated measurements did not interfere with larval responses (Supp. Mat).

\subsection{Experiment 1: Anthropogenic ocean acidification}

The partial pressure of $\mathrm{CO}_{2}\left(p \mathrm{CO}_{2}\right)$ in seawater was adjusted with a high-precision $\mathrm{pCO}_{2}$ control system (Kimoto Electric). Using methods described in Tanaka et al. (2014), fresh filtered seawater (pore size, $1 \mu \mathrm{m}$ ) was treated with a gas mixture of $\mathrm{CO}_{2}$ and ambient air in a bubbling tank. $p \mathrm{CO}_{2}$ of the seawater flowing from the bubbling tank was directly measured and maintained at the desired level by continuously regulating $\mathrm{pCO}_{2}$ in the gas mixture. Three types of seawater were simultaneously prepared using this system: $400 \mathrm{ppm}(\mathrm{pH}$ value $=8.11)$, $700 \mathrm{ppm}(\mathrm{pH}$ value $=7.96)$ and $1000 \mathrm{ppm}(\mathrm{pH}$ value $=7.84)$. These concentrations were chosen to reflect a present day control (400 ppm), and two future scenarios expected by 2050 (700 ppm) and 2100 (1000 ppm) (Feely et al., 2009; Munday et al., 2012; Leduc et al., 2013). The standard deviation of $p \mathrm{CO}_{2}$ and $\mathrm{pH}$ values were $<15 \%$ 
and $<1 \%$ of target values, respectively, which were monitored for 10 days before the experiment (Tanaka et al., 2014). The temperature of the seawater was $27.4{ }^{\circ} \mathrm{C}(\mathrm{SD}=0.2)$.

To test the effect of acidification on the behavioural response towards conspecifics cues, $C$. viridis or S. hispidus larvae were given a choice between conspecifics and heterospecific treated seawater adjusted to one of three acidification levels. Seawater was first acidified to the desired level. Cue treatments were then made by soaking either 5 conspecific or 5 heterospecific individuals in $5 \mathrm{~L}$ of filtered seawater for $3 \mathrm{~h}$. Cue preferences were determined using the $30 \mathrm{C}$. viridis and $15 \mathrm{~S}$. hispidus larvae. Trials run consisted of conspecific vs. heterospecific cue in seawater at: i) $400 \mathrm{ppm}$, ii) an acidified condition (700 or $1000 \mathrm{ppm}$ ), and again iii) $400 \mathrm{ppm}$. Between each consecutive test the larva was maintained in an individual tank of untreated control seawater (400 ppm) for $60 \mathrm{~min}$ (Fig. 1).

A z-test with the null hypothesis that larvae would spend $50 \%$ of their time in either water source was used to determine if marine larvae were significantly i) attracted to conspecifics chemical cues in control
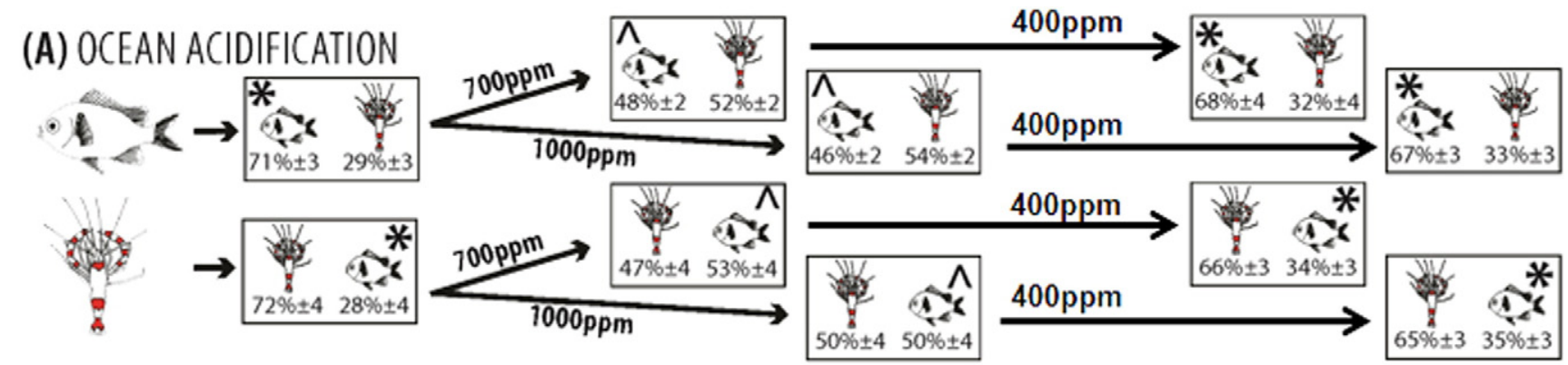

Initial cue preference
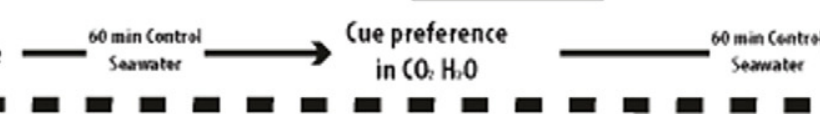

(B) RED SOIL

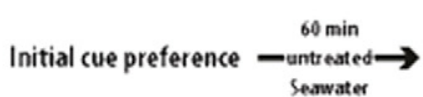

Cue preference
in "dear" soil

a

Initial cue preference Seawater

in "ciear" soil

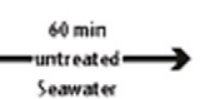

Cue preference
in turbid soil

60 min

untreated

Cue preference

post $\mathrm{C}_{\text {, exposure }}$
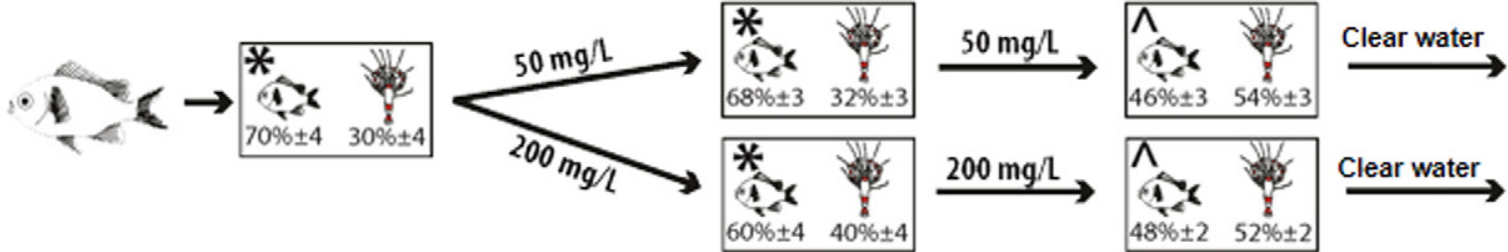

Cue preference post soil exposure
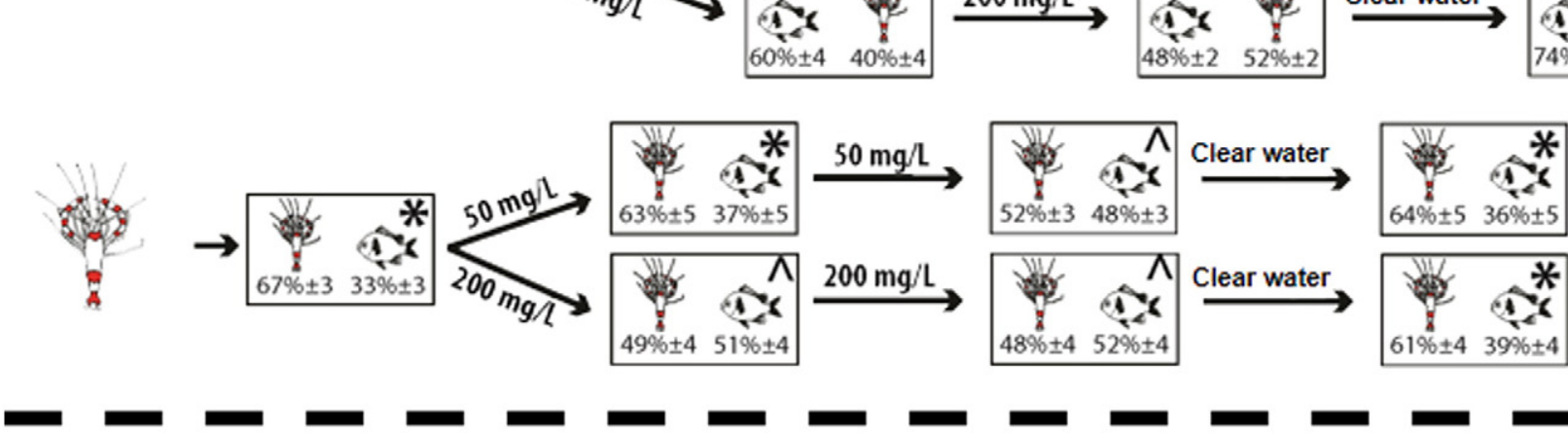

(C) PESTICIDE
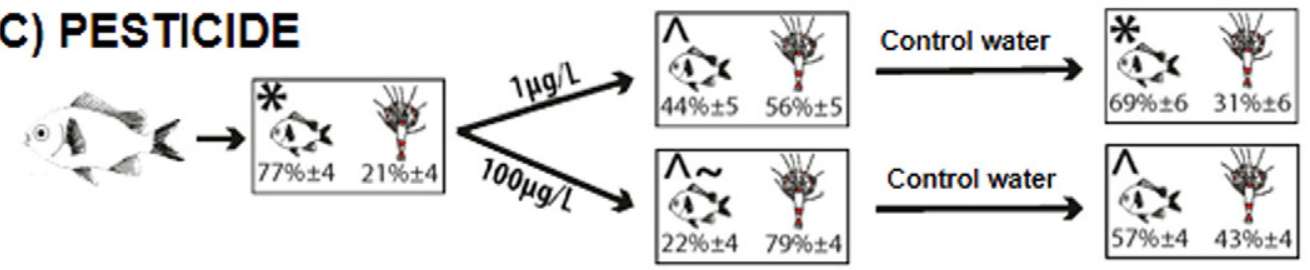

Initial cue preference $\longrightarrow$ Seawater $\rightarrow \begin{gathered}\text { Cue preference } \\ \text { in pesticide }\end{gathered}$

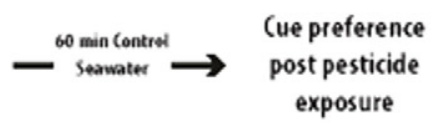

LEGEND

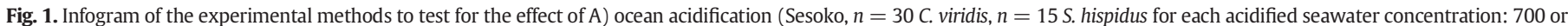

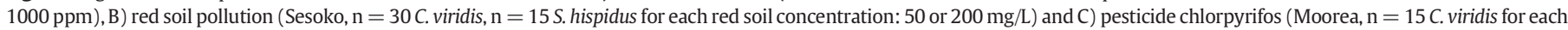

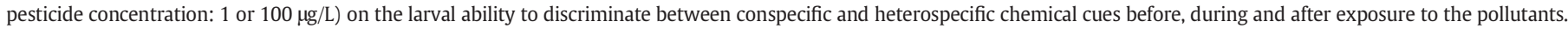

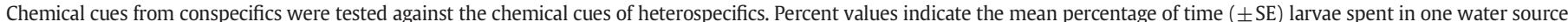

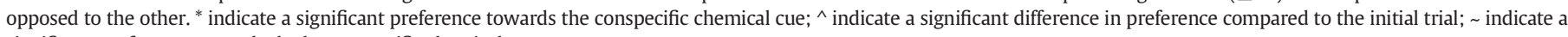
significant preference towards the heterospecific chemical cue. 
conditions, ii) lost the attraction towards the conspecifics cues in acidified seawater ( 700 or $1000 \mathrm{ppm}$ ), and iii) remained attracted towards conspecifics cues in control conditions after exposure to the acidified water. The pairwise comparison between all treatments was analyzed by a generalized linear model (GLM) of fish distribution, followed by post hoc pairwise comparison Dunnet test. Dunnett's test, a post-hoc multiple comparison procedure, is designed to hold the family wise error rate at or below alpha when performing multiple comparisons of treatment group with control. For the same individual repeatedly, the GLM used a repeated measures design. In this case, a correction factor like Bonferroni may be unnecessary.

\subsection{Experiment 2: Red soil treatment}

Two concentrations (50 and $200 \mathrm{mg} / \mathrm{L}$ ) of unpolluted red soil (Kunigami mahgi), obtained from the Okinawa Prefectural Agricultural Research Centre, were tested. The suspended sediment concentration of $<50 \mathrm{mg} / \mathrm{L}$ is regarded as low level pollution in marginal near shore reefs. While $>100 \mathrm{mg} / \mathrm{L}$ is considered a high state of pollution worldwide (Omija, 2004; Fabricius et al., 2005; Wenger et al., 2012). Red soil pollution alters marine systems in two ways; first by introducing additional chemical cues emitted from the red soil into the water column and second, by increasing water column turbidity. Therefore, it was important to experimentally separate the impact of turbidity from the additional of red soil chemical cues.

To test the effect of red soil on the behavioural response towards conspecifics, $C$. viridis or S. hispidus larvae were given a choice between conspecifics seawater and heterospecifics seawater. The same larva was tested four consecutive times i) untreated seawater (control trial), ii) seawater treated with either 50 or $200 \mathrm{mg} / \mathrm{L}$ of settled red soil (testing chemical cues and removing turbidity), iii) seawater treated with either 50 or $200 \mathrm{mg} / \mathrm{L}$ of red soil in turbid water (testing both chemical cues and turbidity) and, iv) untreated seawater (a second control for the exposure to turbidity and red soil chemical cues). Water treatments were created by dissolving red soil into $5 \mathrm{~L}$ of filtered ocean seawater with either 5 conspecifics or 5 heterospecifics for $3 \mathrm{~h}$. The conspecifics and heterospecifics were removed from the tank, and the water sources were left for a further two hours. This allowed the sediment to settle out of solution for the isolation of red soil chemical cues or remain in suspension by adding aeration to test turbidity. Between each test, the larva was maintained in an individual tank supplied with flow-through ocean seawater for $60 \mathrm{~min}$ before being re-tested. The experiment was conducted on $30 \mathrm{C}$. viridis larvae and $20 \mathrm{~S}$. hispidus larvae for each red soil concentration ( 50 or $200 \mathrm{mg} / \mathrm{L}$ ).

\subsection{Experiment 3: Pesticide treatment}

The effect pesticides had on conspecific recognition of $C$. viridis was tested using a seawater control, a solvent control (acetone) and two chlorpyrifos concentrations ( 1 and $100 \mu \mathrm{g} / \mathrm{L}$ ). Chlorpyrifos are one of the most common pesticides found in coral reefs. The concentrations tested reflect levels previous research had identified to inflict negative effects on fish biology, ecology and behavior (Botte et al., 2012). A total of $50 \mathrm{mg}$ of chlorpyrifos was first dissolved into $125 \mathrm{~mL}$ acetone at a final concentration of $400 \mathrm{mg} / \mathrm{L}$ (Botte et al., 2012). To mimiize potential solvent effects, stock concentrations were diluted $10 \mathrm{~L}$ tanks, ensuring acetone volume did not exceed $0.02 \%(\mathrm{v} / \mathrm{v})$.

To test the effect of chlorpyrifos on the behavioural response towards conspecifics cues, 15C. viridis larvae per concentration level were given a choice between conspecifics treated seawater and heterospecifics treated seawater. The same larva was tested three consecutive times i) using untreated filtered seawater (control), ii) using filtered seawater with 1 or $100 \mu \mathrm{g} / \mathrm{L}$ of pesticides, and iii) using untreated filtered seawater (control for previous pesticide exposure). Between each test, the larva was maintained in an individual tank of untreated filtered seawater for $60 \mathrm{~min}$. Additionally, to determine any effect exposure to acetone may have had on fish behavioural preferences, 10 $C$. viridis larvae were given the choice between untreated filtered seawater and filtered seawater containing acetone $(125 \mathrm{~mL}$ of acetone in 10 L of sea-water; z-test).

\subsection{Sample preparation and analysis of seawater chemical fingerprints}

High performance liquid chromatography (HPLC) was used to acquire the profiles of seawater metabolites. This allowed the comparison of the chemical fingerprints of conspecifics between untreated seawater and the different experimental treatments (acidification, red soil, and pesticides). Water samples were prepared by holding 10 juvenile $C$. viridis for $3 \mathrm{~h}$ in $10 \mathrm{~L}$ of: i) filtered untreated seawater at each location (Moorea and Sesoko), ii) seawater treated to either 400, 700 or 1000 ppm CO 2 , iii) "clear" seawater made with either 50 or $200 \mathrm{mg} / \mathrm{L}$ settled red soil, iv) turbid seawater made with either 50 or $200 \mathrm{mgL}^{-1}$ of red soil and lastly, v) seawater with 1 or $100 \mu \mathrm{g} / \mathrm{L}$ of chlorpyrifos. Each water sample ( $10 \mathrm{~L})$ was vacuum filtered through solid phase extraction (SPE) cartridges containing $\mathrm{C}_{18}$ silica-gel-based bonded phase sorbent, washed with $50 \mathrm{~mL}$ distilled water, and subsequently desorbed with $50 \mathrm{~mL}$ methanol. The organic phase of each sample was freezedried leaving a powdery organic residue. The organic extracts were dissolved in $1 \mathrm{~mL}$ methanol before analysis. The data were processed to create a max plot chromatogram that plotted the maximum spectral absorbance measured at each time point. Max plot chromatogram detects all UV-absorbing components in a sample. The absorbance of each component (computed as the area of peak and expressed in absorbance units, AU) was used to identify the molecular diversity of conspecifics odor in presence or absence of acidified seawater, red soil or pesticides.

\section{Results}

\subsection{Experiment 1: Anthropogenic ocean acidification}

Both $C$. viridis and S. hispidus displayed a significant attraction to the chemical cues of conspecifics when tested against the chemical cues of heterospecifics under current day conditions ( $400 \mathrm{ppm}$; $\mathrm{z}$ test, $p$ value $<0.001$ for both taxa; Fig. $1 \mathrm{~A}$ ). Larvae spent $\sim 70 \%$ of their time in the chemical cue containing the conspecific cue opposed to seawater containing heterospecific cues (mean $\% \pm S E$; $C$. viridis: $71 \pm 3.2 \%$; . hispidus: $70 \pm 3.5 \%$ ). However, when seawater was treated to a either $700 \mathrm{ppm}$ or $1000 \mathrm{ppm} \mathrm{CO}_{2}$, this attraction was significantly reduced. When compared to the initial present day control trial, $C$. viridis displayed a $>23 \%$ decreased attraction and S. hispidus decreased conspecific attraction by $>25 \%$ (GLM, $p<0.001$; Dunnet test, $\mathrm{p}<0.001$ for both taxa). Furthermore, at both $700 \mathrm{ppm}$ or $1000 \mathrm{ppm} \mathrm{CO}_{2}$, marine larvae lost their attraction towards the conspecific cue, spending equal time in water containing either the conspecific or heterospecifc signal $(z$ test, $p>0.19$ for both taxa).

Larvae of both species, previous exposed to either $700 \mathrm{ppm}$ or $1000 \mathrm{ppm} \mathrm{CO}$, regained their preference for conspecific chemical signals when tested for a third time in present day (400 ppm) conditions (C. viridis: $68 \pm 3.5 \%$; S. hispidus: $66 \pm 3.0 \%$; $z$ test, $p<0.003$ for both taxa; Fig. 1A). C. viridis and S. hispidus larvae displayed no significant difference between their initial $400 \mathrm{ppm}$ trial and the final $400 \mathrm{ppm}$ experimental trial (Dunnet test, $p=0.97$ for $C$. viridis, $p=0.94$ for S. hispidus).

\subsection{Experiment 2: Red soil treatment}

C. viridis and S. hispidus larvae displayed signficiant preferences towards the chemical cues of conspecifics opposed to heterospecifics prior to red soil exposure (C. viridis: $70 \pm 3.6 \%$ and S. hispidus: $67 \pm$ 3.1\%; Fig. 1B).

Preferences for the conspecific chemical signal persisted in both species when experiment trials were run in water treated with $50 \mathrm{mg} / \mathrm{L}$ of red soil that was allowed to precipitate out of solution (Fig. 1B). The 
attraction towards conspecific cues was reduced by $2 \%$ for $C$. viridis and $4 \%$ for S. hispidus (GLM $p<0.001$; Dunnet test $C$. viridis $p=0.98$; $S$. hispidus $p=0.55$ ). $C$. viridis was able to maintain a significant preference for the conspecific chemical cue when the red soil concentration was increased to $200 \mathrm{mg} / \mathrm{L}$ ( $\mathrm{z}$ test, $p=0.03$ ). However, the preference for the conspecific cue decreased from $70 \%$ to $60 \%$ (Fig. 1B). In contrast, $S$. hispidus lost their preference for the conspecific chemical cue when the amount of red soil was increased to $200 \mathrm{mg} / \mathrm{L}$ ( $\mathrm{z}$ test, $p=0.16$ ) with the preference for the conspecific cue decreased from $67 \%$ to $49 \%$ (Fig. 1B).

In the turbid water treatment containing both the chemical cues and turbidity of the red soil, regardless of soil concentration $50 \mathrm{mg} / \mathrm{L}$ or $200 \mathrm{mg} / \mathrm{L}$, the attraction towards conspecific cues was significantly reduced in both species compared to the initial trial with no red soil (Fig. 1B). The turbidity associated with $50 \mathrm{mg} / \mathrm{L}$ red soil significantly reduced the time spent in conspecific chemical cues by $24 \%$ for $C$. viridis and $19 \%$ for $S$. hispidus (Dunnet test, $p<0.001$ for both taxa). Resulting in a loss of chemical attraction behavior in both $C$. viridis and S. hispidus larvae at $50 \mathrm{mg} / \mathrm{L}$ ( $z$ test, $p>0.43$ for both taxa) and $200 \mathrm{mg} / \mathrm{L}$ red soil ( $\mathrm{z}$ test, $p>0.17$ for both taxa).

Larvae were retested for their chemical preferences of conspecific vs. heterospecific cues post exposure to either levels of red soil (50 or $200 \mathrm{mg} / \mathrm{L}$ ) and exposure types (chemical cue only and turbid red soil water). Both species significantly regained attraction to conspecifics chemical cues ( $p<0.02$ for all tests). There were no significant differences in the strength of their cue preference between the initial control and final post exposure control trials ( $p>0.90$ for all tests).

\subsection{Experiment 3: Pesticide treatment}

Exposure to acetone had no effect on the choice behavior of $C$. viridis larvae (mean \pm SE percentage of time spent in the control flow: $54 \pm$ $2.1 \%$ - $z$ test, $p=0.85$ ). As expected by previous results, initial preferences demonstrated a significant attraction towards the chemical cues of conspecifics compared to heterospecifics (Fig. 1C).

Exposure to seawater treated with $1 \mu \mathrm{g} / \mathrm{L}$ of chlorpyrifos reduced the attraction towards conspecific cues by $33 \%$, resulting in C. viridis larvae no long spending significantly more time in the conspecific cue choice ( $z$ test, $p=0.29$ ). Time spent in the conspecific cue was further reduced in seawater treated with $100 \mu \mathrm{g} / \mathrm{L}$ of chlorpyrifos. C. viridis initially spent $77 \%$ of their time in the seawater containing chemical cues of the conspecific. However, $100 \mu \mathrm{g} / \mathrm{L}$ of chlorpyrifos reduced the amount of time spent in conspecific water to only $22 \%$. Unlike all other anthropogenic experimental trials, exposure to $100 \mu \mathrm{g} / \mathrm{L}$ altered the chemical preference of $C$. viridis so greatly that fish in this treatment displayed a significant preference for heterospecific opposed to conspecific chemical cues ( $\mathrm{z}$ test, $p<0.001$ ).

In the post exposure control trial (without pesticide), larvae previously exposed to $1 \mu \mathrm{g} / \mathrm{L}$ chlorpyrifos were significantly attracted to the conspecific chemical cues ( $\mathrm{z}$ test, $p=0.01$ ) and no significant difference was found in the strength of their preference between the initial and post exposure control trials (Dunnet test, $p$-value $=0.36$ ). Recovery of chemical preference was not shown in $C$. viridis that had been exposed to $100 \mu \mathrm{g} / \mathrm{L}$, individuals did not significantly prefer the chemical cues of conspecifics, spending only $57 \%$ of their time this cue (z test, $p=$ 0.06 ). As a result, cue preference was significantly different when comparing pre and post exposure control trials (Dunnet test, $p=0.04$ ).

\subsection{Analysis of seawater chemical fingerprints}

HPLC determined the chemical fingerprints of $C$. viridis in presence or absence of acidified seawater, red soil and pesticides (Figs. 2,3,4). Three control seawater samples (no anthropogenic treatments or conspecifics) were characterized by very few minor peaks. Therefore, each peak found was due to the odor of conspecifics rather than the seawater itself.
In acidification treatments, the chemical fingerprint of conspecifics at $400 \mathrm{ppm}$ was characterized by two major peaks (noted 1 and 2 in Fig. 2) and one peak complex (noted 3 in Fig. 2). At 700 ppm and $1000 \mathrm{ppm} \mathrm{CO}$, the fingerprint still contained one major peak (noted 2 ) and one peak complex (noted 3). However, the absorbance of each peak decreased: from $5.37 \mathrm{AU}$ at $400 \mathrm{ppm}$ to $5.44 \mathrm{AU}$ at $1000 \mathrm{ppm}$ for the peak 2; and from $7.28 \mathrm{AU}$ at $400 \mathrm{ppm}$ to $6.54 \mathrm{AU}$ at $1000 \mathrm{ppm}$. No significant variation was highlighted between the absorbance of each peak and acidified water (no significant regression, slope $=0.0001$, $p=0.97$ for peak 2 ; slope $=-0.001, p=0.72$ for peak 3 ). Interestingly, the peak noted 1 at $400 \mathrm{ppm}(0.56 \mathrm{AU})$ disappeared in seawater treated to $700 \mathrm{ppm}$ and $1000 \mathrm{ppm}$; and a new minor peak appeared at 1000 ppm (0.08 AU; noted A in Fig. 2).

The chemical fingerprint of conspecific cues in the absence of red soil was characterized by three major peaks (noted 1 to 3 in Fig. 3 ) and one peak complex (noted 4 in Fig. 3). The fingerprint of unpolluted red soil (Kunigami mahgi) did not show any peaks. In presence of red soil, the chemical fingerprint of conspecific cues was still characterized by the one major peak and one peak complex (noted 2 and 4). No significant variation was found between the peak absorbance and red soil concentration. The first major peak (noted 1, $0.18 \mathrm{AU}$ ) disappeared when red soil was added at any concentration and the third peak (noted 3) was only present on the chromatograms of $50 \mathrm{mg} / \mathrm{L}$ red soil (0.98 AU without red soil, $0.28 \mathrm{AU}$ in clear water, and $0.85 \mathrm{AU}$ in turbid water). Two peaks appeared in presence of red soil: a minor peak (noted $A$, from 0.13 to $0.33 \mathrm{AU}$ ) on all chromatograms and a major peak (noted $\mathrm{B}$, $2.22 \mathrm{AU}$ ) on the chromatogram of $50 \mathrm{mg} / \mathrm{L}$ red soil in clear water (Fig. 3).

The chemical fingerprint of conspecifics in the absence of a pesticide was characterized by seven major peaks (noted 1 to 7 in Fig. 4) and one peak complex (noted 8 in Fig. 4). The fingerprint of chlorpyrifos was characterized by one major peak at $18^{\prime} 31 \mathrm{~min}$ (4.79 AU). This peak was present on the fingerprint of conspecifics at $1 \mu \mathrm{g} / \mathrm{L}(0.28 \mathrm{AU})$ and $100 \mu \mathrm{g} / \mathrm{L}$ (5.10 AU). In presence of $1 \mu \mathrm{g} / \mathrm{L}$ pesticides, the fingerprint of conspecific chemical cues was characterized by a decrease in absorbance of all but one peak (peak 7) and the disappearance of 1 peak (noted 6) and the peak complex (noted 8). For example, the absorbance of peak 1 was reduced 10 -fold (from $12.8 \mathrm{AU}$ to $1.2 \mathrm{AU}$ ). One minor peak appeared in seawater treated with $1 \mu \mathrm{g} / \mathrm{L}$ pesticides (noted A in Fig. 4). In presence of $100 \mu \mathrm{g} / \mathrm{L}$ pesticides, the chemical fingerprint of conspecific cues was characterized by virtually no peaks, with the exception of two (noted 1 and 7), both had low absorbance reduced by 11 and 18 fold respectively (Fig. 4).

\section{Discussion}

Anthropogenic induced stressors, such as ocean acidification, sedimentation/turbidity, and pesticide runoff result in direct consequences for coral reef habitats. These anthropogenic alterations also impact the ability of larvae during the recruitment stage to recognize and respond to the chemical cues used for habitat identification. The use of chemical cues in habitat selection (Kingsford et al., 2002; Dixson et al. 2014; Barth et al., 2015) and the importance of conspecific chemical cues has been widely accepted (Kingsford et al., 2002; Dixson et al., 2011; Coppock et al. 2013; Lecchini and Nakamura 2013; Barth et al., 2015). Results collected here, confirm an attraction towards conspecific opposed to heterospecific chemical cues, in fish (C. viridis) and crustacean ( $S$. hispidus) larvae. However, when chemical cues were exposed to anthropogenic induced stressors (ocean acidification, sedimentation/turbidity, and pesticide runoff), waterborne chemical information is altered. This change results in fish and crustacean larvae no longer displaying an attraction towards important conspecific chemical signatures. The reduced attraction could result in decreased recruitment to reefs experiencing said stressors.

Fish and shrimp larvae lost their chemical attraction to conspecifics cues in seawater treated to mimic conditions expected to occur in 50-100 years (Fig. 1A). The larval attraction was reduced by $23 \%$ in 


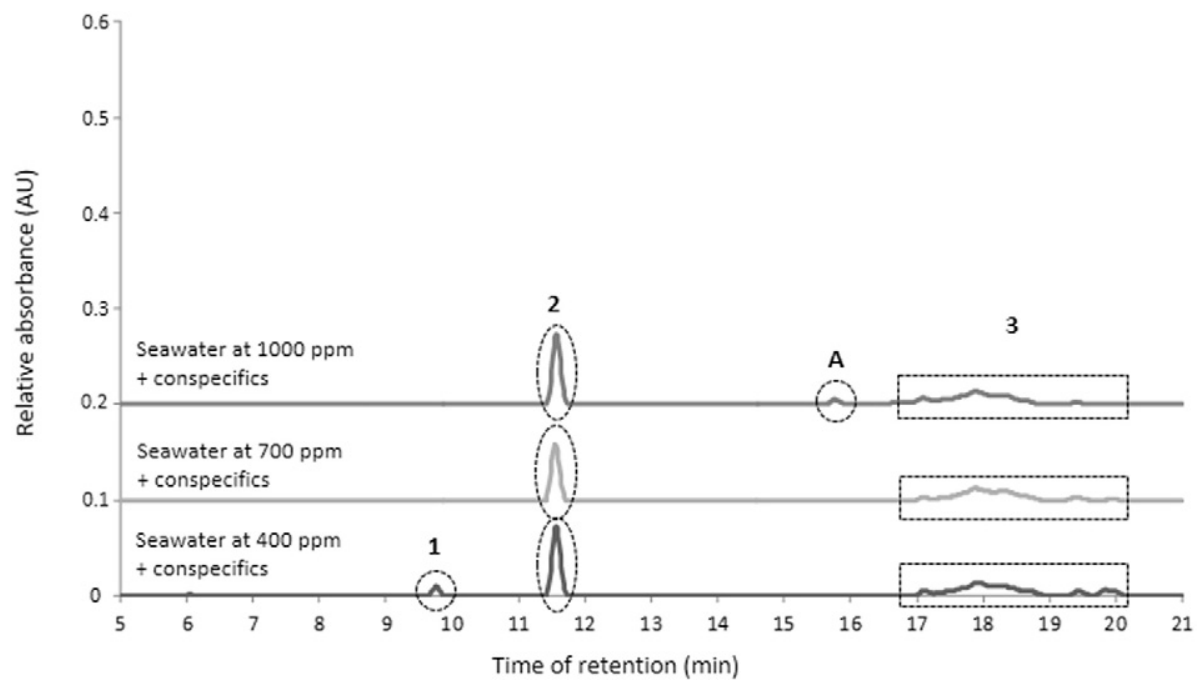

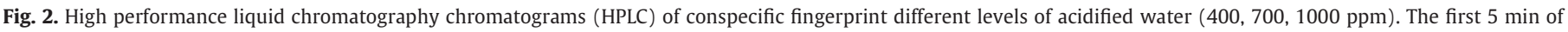

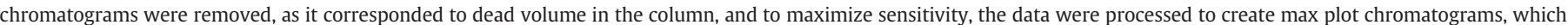

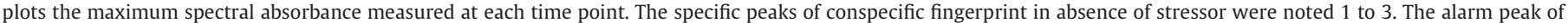
conspecifics emitted in polluted environment was noted $\mathrm{A}$.

either $700 \mathrm{ppm}$ or $1000 \mathrm{ppm} \mathrm{CO}_{2}$ seawater when compared to a present day control condition (400 ppm). Similarly, Amphiprion percula (clownfish) larvae reared in seawater simulating future ocean acidification conditions, resulted in the inability of larvae to discriminate between predators and non-predators (Dixson et al. 2010) and parents and non-parents (Munday et al. 2009). Our results are consistent with previous studies, demonstrating an acidification induced effect on fish behavior and the perception of chemical cues (Dixson et al. 2010, Munday et al. 2012; Heuer and Grosell, 2014).

Red soil also affected the chemical abilities of marine larvae to recognize their conspecifics (Fig. 1B). When red soil was suspended in water and allowed to precipitate from the water column, leaving red soil chemical cues but removing turbidity, the larval attraction to conspecifics was only lost for S. hispidus at high concentrations $(200 \mathrm{mg} / \mathrm{L})$ of red soil. Both $C$. viridis and S. hispidus were able to recognize and respond to conspecific cues at the lower concentration tested $(50 \mathrm{mg} / \mathrm{L})$.
While the "clear" red soil treatment no longer contains the red soil particulates, it does contain the waterborne chemical components produced by each concentration level of red soil within the water column. In contrast, $C$. viridis and S. hispidus larvae lost their chemical attraction to conspecific cues in turbid water at both $50 \mathrm{mg} / \mathrm{L}$ and $200 \mathrm{mg} / \mathrm{L}$ of red soil. A reduction in fish abundance, biomass and species diversity has been documented at inshore sites and sites highly impacted by sediment compared to offshore or low sediment sites (Fabricius et al., 2005; Mallela et al., 2007). Our results indicate that crustacean and fish larvae are more chemically sensitive to water turbidity (i.e. sedimentation) than the chemical pollution of red soil (Fig. 1B). Similarly, an increase in turbidity (suspended sediment levels $>45 \mathrm{mg} / \mathrm{L}$ ) impaired habitat choice and foraging success of coral reef fish recruits due to reduced ability to distinguish visual and chemical cues (Wenger et al., 2012, 2015; O'Connor et al., 2016). Importantly, the rainy season corresponds with a high recruitment levels on the Great

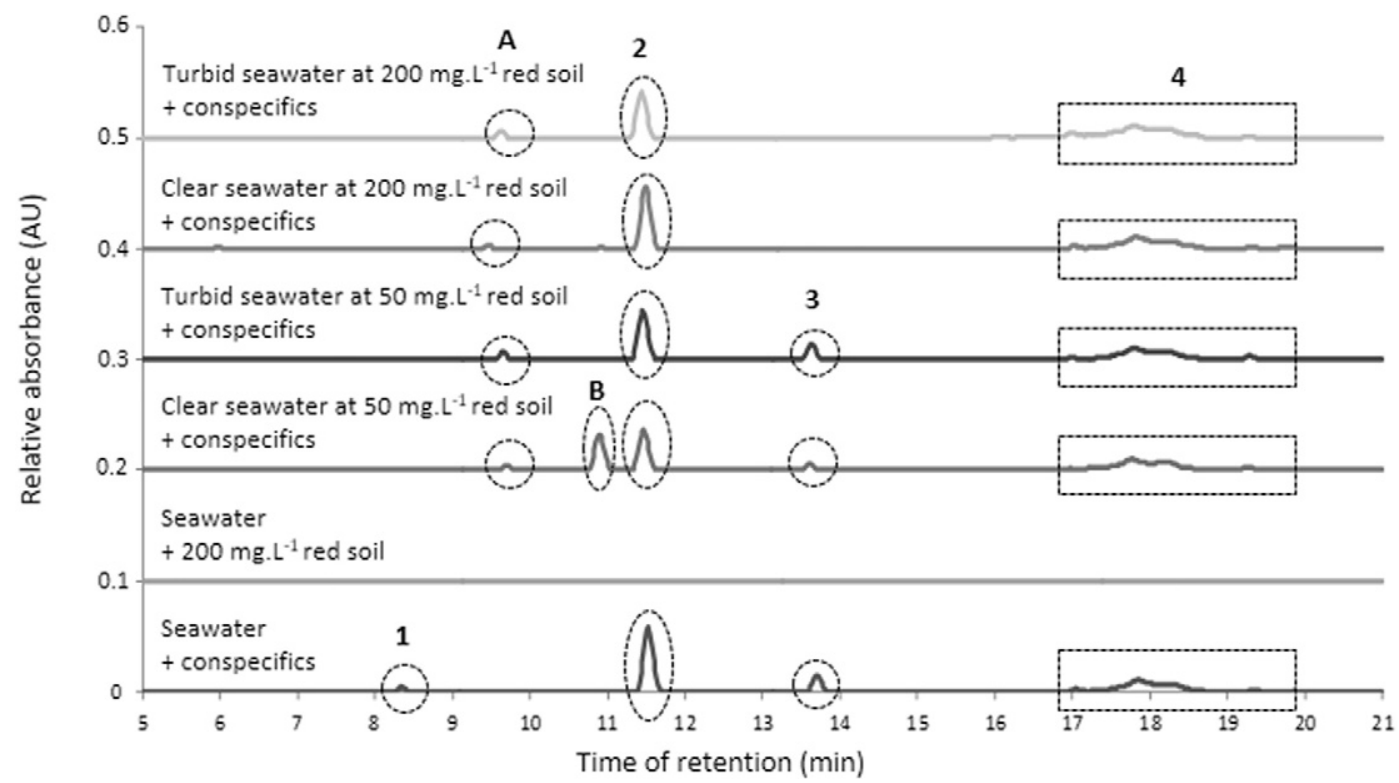

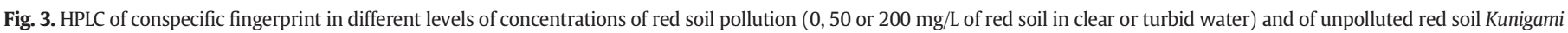
mahgi. The specific peaks of conspecific fingerprint in absence of stressor were noted 1 to 4 . The alarm peaks of conspecifics emitted in polluted environment was noted A and B. 


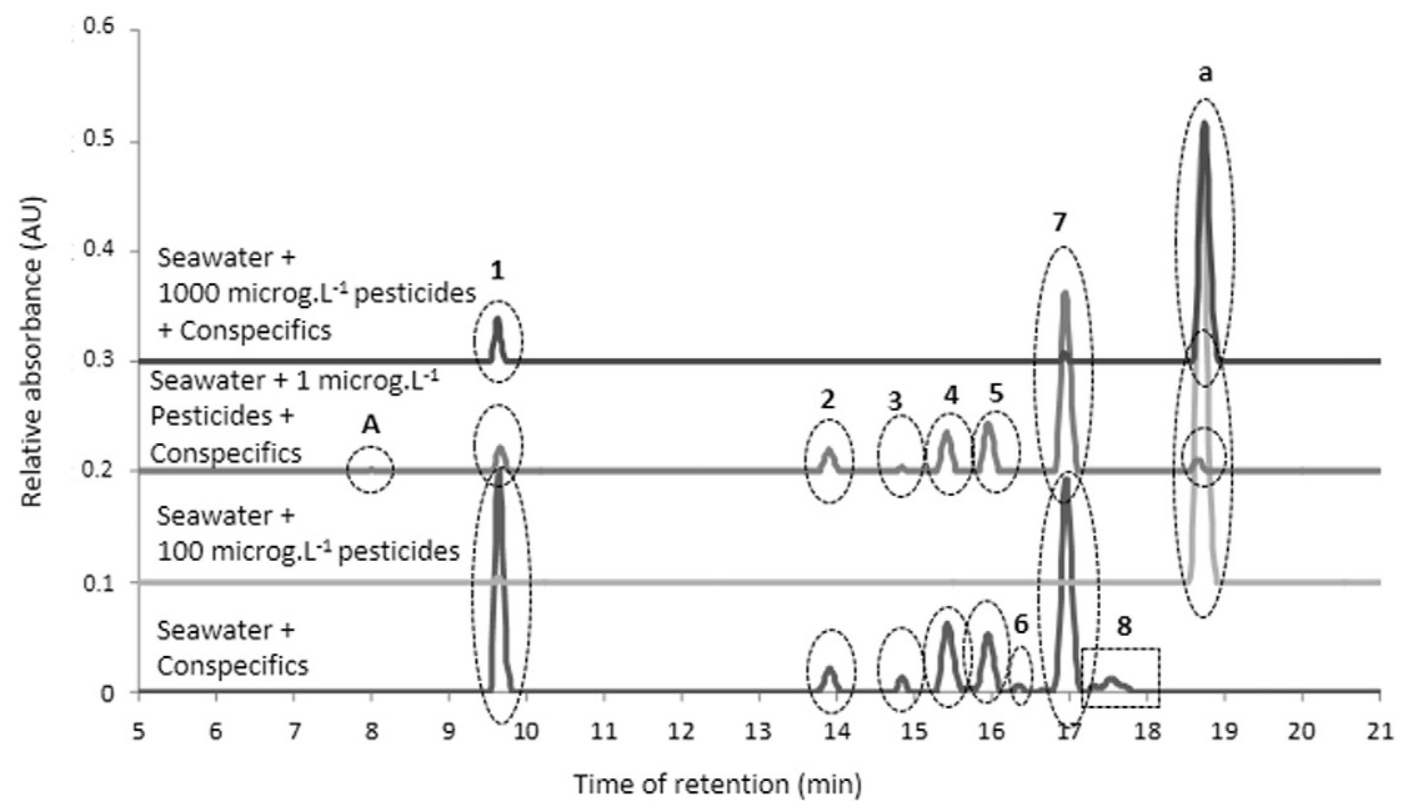

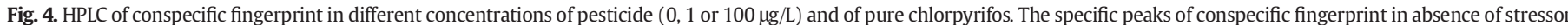
were noted 1 to 8 . The alarm peak of conspecifics emitted in polluted environment was noted A. The specific peak of chlorpyrifos was noted 'a'.

Barrier Reef, Ryukyu Island, and French Polynesia (Nakamura et al., 2009a; Lo-Yat et al., 2011); meaning fish and crustacean larvae experience sub-optimal conditions during recruitment as sedimentation is increased due to precipitation induced runoff.

In addition to terrestrial runoff, some pesticides, used in agriculture, are carried into coral lagoons, as in Moorea Island (Roche et al., 2011). Toxicology research in coral reefs have focused on the pesticide concentration found the tissue of different marine organisms (Roche et al., 2011). Few studies highlighted the influence of pesticides on biology, ecology and ontogenetic development of coral and fishes (Fabricius et al., 2005; Botte et al., 2012). No studies to date have tested the impact of pollutants on recruitment cues used by settlement stage larvae. $C$. viridis larvae significantly lost their ability to chemically recognize conspecifics cues at $1 \mu \mathrm{g} / \mathrm{L}$ and $100 \mu \mathrm{g} / \mathrm{L}$ chlorpyrifos (Fig. 1C). Moreover, among all anthropogenic treatments studied, exposure to the $100 \mu \mathrm{g} / \mathrm{L}$ chlorpyrifos pesticide had lasting effects on $C$. viridis. Fish were unable to recognize conspecific chemical cues after pesticide exposure when tested in untreated filtered seawater.

Although several studies suggest the presence of alarm cues emitted as a signal of stress (Barth et al., 2015), no studies in coral reefs have explored the effects of human pollution on social interactions (e.g., reproduction, recruitment, foraging activities - Leis et al., 2011). Coral reef fish and crustaceans are exposed to an enormous diversity of chemical cues that are mixed and dispersed by waves, currents, and tides. Therefore, extracting useful information from multiple cues is crucial to the survival of marine organisms (Barth et al., 2015). It has been shown that the chemical cues from specific reef components can impact recruitment, with coral acting as a positive cue and seaweed acting as a negative source of chemical stimuli (Dixson et al. 2014). Lecchini et al. (2013) found, during the recruitment stage, 70\% of the fish species preferred water from reefs dominated by live coral compared to reefs dominated by algae. It was suggested that fish larvae could respond to the quantity of chemical cues emitted by conspecifics whose abundance changes in response to coral and algal cover, or the chemical cues varied based on the environment. Here, we demonstrate the latter, showing a modification of the chemical fingerprints of conspecifics according to the environment (Figs. 2,3,4). In acidification and red soil treatments, conspecific fingerprints were modified with a disappearance of some peaks and the appearance of some 'alarm' peaks (i.e. emission of metabolic disturbance factors). For example, at $700 \mathrm{ppm} \mathrm{CO}_{2}$, there was a disappearance of peak noted 1 (Fig. 2), which suggest that conspecific behavior is altered by acidified water. At $1000 \mathrm{ppm} \mathrm{CO}_{2}$, there was the appearance of one peak noted A (Fig. 2), suggesting the production of alarm cues by conspecifics. Similarly, two peaks appeared in the presence of red soil, a minor peak A (from 0.13 to $0.33 \mathrm{AU}$ ) on all chromatograms and a major peak B ( $2.22 \mathrm{AU}$ ) on the chromatogram of $50 \mathrm{mg} / \mathrm{L} \mathrm{in}$ water containing the chemical cues of red soil alone (Fig. 3 ). The presence of alarm peaks in the red soil experiments did not inhibit the larval attraction towards conspecific cues, suggesting alarm signals are minor compared to the cue of conspecific juveniles. In the $1 \mu \mathrm{g} / \mathrm{L}$ pesticide treatment, the conspecific chemical fingerprint was modified with a decrease in absorbance of nearly all peaks, the disappearance of two peaks and the appearance of one alarm peak (Fig. 4). At a concentration of $100 \mu \mathrm{g} / \mathrm{L}$ pesticide, the conspecific chemical fingerprint contained only two peaks at low absorbance (Fig. 4). These results suggest that conspecific behavior was altered by the presence of $1 \mu \mathrm{g} / \mathrm{L}$ pesticides with the release of alarm cues. At $100 \mu \mathrm{g} / \mathrm{L}$ pesticides, conspecific cues were so strongly altered that almost no chemical signal was emitted into the seawater. Consequently, the larval attraction for conspecific chemical signals was decreased. Overall, these results highlight, for the first time, that polluted seawater modified the specific chemical signature of conspecifics. A weak stressor evoked the production of alarm cues, a strong stressor resulted in reduced cue emission.

Our results highlight that both global (ocean acidification) and local stressors (red soil and pesticides) to coral reef ecosystems could have significant effects on the sustainability of reefs by altering the behavior of fish and crustacean populations during a critical life-history transition (i.e. recruitment phase). In chemical polluted environments, marine larvae displayed a reduced or no attraction to conspecifics, thus larvae may not locate suitable settlement habitat, resulting higher predation and lower recruitment levels. Predicting how anthropogenic changes will affect connectivity and recruitment in coral reef ecosystems is important. The dispersal of larvae between reefs is a key component in population dynamics of reef organisms and reef connectivity (Munday et al., 2009). Our study investigated non-lethal behavioural effects of chemical cues in changing environments. Although the levels of ocean acidification, pesticide pollution and terrestrial runoff did not result in mortality among the exposed organisms, indirect consequences were found. Thus, if polluted seawater disrupts the recruitment process, fish larvae may misinterpret important chemical signals resulting in lower 
recruitment levels to impacted reefs. Stability of marine organisms is dependent, in part, on the stability of social interactions. Therefore disruption to larvae-conspecifics relationships could have major consequences for recruitment and adult population with further repercussions for the ecosystem. Understanding the relationship between reef health and recruitment potential could allow management planning for the maintenance of coral cover and biodiversity on reefs that are increasingly degraded.

\section{Competing interests}

The authors have declared no competing interests exist.

\section{Author contributions}

D.L., Y.T., B.B. and Y.N. designed research; D.L., G.L., D.L.D., N.R., B.F., M.B. and Y.N. collected and analyzed data; D.L., G.L., D.L.D. and Y.N. wrote the paper.

\section{Acknowledgements}

This study was supported by grants from Japan Society for the Promotion of Science (No. 24780188, 23241017 and 26220102) and the Alfred P. Sloan Foundation (DLD). The methods of all the experiments conducted in the present study were carried out in accordance with the approved guidelines of the French Polynesia and Japan committee for publication ethics. All experimental protocols were approved by the ethics committee of CRIOBE at Moorea and of Tropical Biosphere Research Center at Okinawa.

\section{Appendix A. Supplementary data}

Supplementary data to this article can be found online at http://dx. doi.org/10.1016/j.marpolbul.2016.08.083.

\section{References}

Barth, P., Berenshtein, I., Besson, M., Roux, N., Parmentier, E., Banaigs, B., Lecchini, D., 2015 From the ocean to a reef habitat: how do the larvae of coral reef fishes find their way home? A state of art on the lastest advances. Life Environment 65, 91-100.

Botte, E.S., Jerry, D.R., King, S.C., Smith-Keune, C., Negri, A.P., 2012. Effects of chlorpyrifos on cholinesterase activity and stress markers in the tropical reef fish Acanthochromis polyacanthus. Mar. Pollut. Bull. 14, 21-32.

Chin, A., Lison De Loma, T., Reytar, K., Planes, S., Gerhardt, K., Clua, E., Burke, L., Wilkinson, C., 2011. Status of Coral Reefs of the Pacific and Outlook: 2011. Publishers Global Coral Reef Monitoring Network.

Coppock, A.G., Gardiner, N.M., Jones, G.P., 2013. Olfactory discrimination in juvenile coral reef fishes: response to conspecifics and corals. J. Exp. Mar. Biol. Ecol. 443, 21-26.

de Groot, R., Brander, L., van der Ploeg, S., Costanza, R., 2012. Global estimates of the value of ecosystems and their services in monetary units. Ecosystem Services 1, 50-61.

Dixson, D.L., Munday, P.L., Jones, G.P., 2010. Ocean acidification disrupts the innate ability of fish to detect predator olfactory cues. Ecol. Lett. 13, 68-75.

Dixson, D.L., Jones, G.P., Munday, P.L., Pratchett, M.S., Srinivasan, M., Planes, S., Thorrold, S.R., 2011. Terrestrial chemical cues help coral reef fish larvae locate settlement habitat surrounding islands: coral reef fish larvae use land cues for settlement. Ecology and Evolution 1, 586-595.

Dixson, D.L., Pratchett, M.S., Munday, P.L., 2012. Reef fishes innately distinguish predators based on olfactory cues associated with recent prey items rather than individual species. Anim. Behav. 84, 45-51.

Dixson, D.L., Abrego, D., Hay, M.E., 2014. Chemically mediated behavior of recruiting corals and fishes: a tipping point that may limit reef recovery. Science 345, 892-897.

Doherty, P.J., 2002. Variable Replenishment and the Dynamics of Reef Fish Populations. In: Sale, P.F. (Ed.), Coral Reef Fishes: Dynamics and Diversity in a Complex Ecosystem. Academic press, San Diego, pp. 327-358.

Doherty, P.J., Dufour, V., Galzin, R., Hixon, M.A., Planes, S., 2004. High mortality at settlement is a population bottleneck for a tropical surgeonfish. Ecology 85, 2422-2428.
Fabricius, K.E., 2005. Effects of terrestrial runoff on the ecology of corals and coral reefs: review and synthesis. Mar. Pollut. Bull. 50, 125-146.

Fabricius, K., De'ath, G., McCook, L., Turak, E., Williams, D.M.B., 2005. Changes in algal, coral, and fish assemblages along water quality gradients on the inshore great barrier reef. Mar. Pollut. Bull. 51, 384-398.

Feely, R.A., Doney, S.C., Cooley, S.R., 2009. Ocean acidification: present conditions and future changes in a high-CO2 world. Oceanography 22, 36-47.

Gerlach, G., Atema, J., Kingsford, M.J., Black, K.P., Miller-Sims, V., 2007. Smelling home can prevent dispersal of reef fish larvae. Proc. Natl. Acad. Sci. 104, 858-863.

Grigg, R.W., Dollar, S.J., 1990. Natural and anthropogenic disturbance on coral reefs. Ecosystems World 25, 439-452.

Hanski, I., Gilpin, M.E., 1997. Metapopulation Biology: Ecology, Genetics and Evolution. Academic Press, London.

Heuer, R.H., Grosell, M., 2014. Physiological impacts of elevated carbon dioxide and ocean acidification on fish. Am. J. Physiol. Regul. Integr. Comp. Physiol. 307, 1061-1084.

Hughes, T.P., Baird, A.H., Bellwood, D.R., Card, M., Connolly, S.R., 2003. Climate change, human impacts, and the resilience of coral reefs. Science 301, 929-933.

Jones, G.P., McCormick, M.I., Srinivasan, M., Eagle, J.V., 2004. Coral decline threatens fish biodiversity in marine reserves. Proc. Natl. Acad. Sci. 101, 8251-8253.

Kingsford, M.J., Leis, J.M., Shanks, A., Lindeman, K.C., Morgan, S.G., Pineda, J., 2002. Sensory environments, larval abilities and local self-recruitment. Bull. Mar. Sci. 70, 309-340.

Lecchini, D., 2005. Spatial and behavioural strategies used by coral reef fish post-larvae to integrate into their settlement habitat. Mar. Ecol. Prog. Ser. 301, 247-252.

Lecchini, D., Nakamura, Y., 2013. Use of chemical cues by coral reef animal larvae for habitat selection. Aquat. Biol. 19, 231-238.

Lecchini, D., Dufour, V., Carleton, J., Strand, S., Galzin, R., 2004. Study of the fish larval flux at Moorea Island: is the spatial scale significant? J. Fish Biol. 65, 1142-1146.

Lecchini, D., Polti, S., Nakamura, Y., Mosconi, P., Tsuchiya, M., Remoissenet, G., Planes, S., 2006. New perspectives to aquarium fish trade. Fish. Sci. 72, 40-47.

Lecchini, D., Mills, S.C., Brié, C., Maurin, R., Banaigs, B., 2010. Ecological determinants and sensory mechanisms in habitat selection of crustacean larvae. Behav. Ecol. 21, 599-607.

Lecchini, D., Waqalevu, V.P., Parmentier, E., Radford, C.A., Banaigs, B., 2013. Fish larvae prefer coral above algal water cues: implications of coral reef degradation. Mar. Ecol. Prog. Ser. 475, 303-307.

Leduc, A.O Munday, P.L, Brown, G.E., Ferrari, M.C. 2013. Effects of acidification on olfactory-mediated behaviour in freshwater and marine ecosystems: a synthesis. Philosophy Trans Royal Society Biological Science 368, 13-20.

Leis, J.M., Siebeck, U., Dixson, D.L., 2011. How Nemo finds home: the neuroecology of dispersal and of population connectivity in larvae of marine fishes. Integr. Comp. Biol. $51,826-843$

Lo-Yat, A., Simpson, S.D., Meekan, M., Lecchini, D., Martinez, E., Galzin, R., 2011. Extreme climatic events reduce ocean productivity and larval supply in a tropical reef ecosystem. Glob. Chang. Biol. 17, 1695-1702.

Mallela, J., Roberts, C., Harrod, C., Goldspink, C.R., 2007. Distributional patterns and community structure of Caribbean coral reef fishes within a river-impacted bay. J. Fish Biol. 70, 523-537.

Munday, P.L., Leis, J.M., Lough, J.M., Paris, C.B., Kingsford, M.J., Berumen, M.L., Lambrechts, J., 2009. Climate change and coral reef connectivity. Coral Reefs 28, 379-395.

Munday, P.L., McCormick, M.I., Nilsson, G.E., 2012. Commentary impact of global warming and rising $\mathrm{CO}_{2}$ levels on coral reef fishes: what hope for the future? J. Exp. Biol. 215, 3865-3873.

Nakamura, Y., Shibuno, T., Lecchini, D., Kawamura, T., Watanabe, Y., 2009a. Spatial variability in habitat associations of pre- and post-settlement stages of coral reef fishes at Ishigaki Island, Japan. Mar. Biol. 156, 2413-2419.

Nakamura, Y., Shibuno, T., Lecchini, D., Watanabe, Y., 2009b. Habitat selection by emperor fish larvae. Aquat. Biol. 6, 61-65.

O'Connor, J.J., Lecchini, D., Beck, H.J., Cadiou, G., Lecellier, G., Booth, D.J., Nakamura, Y., 2016. Sediment pollution impacts sensory ability and performance of settling coralreef fish. Oecologia 180, 11-21.

Omija, T., 2004. Terrestrial inflow of soils and nutrients. Coral Reefs of Japan 47, 64-68.

Roche, H., Salvat, B., Ramade, F., 2011. Assessment of the pesticides pollution of coral reefs communities from French Polynesia. Revue d'Ecologie 22, 3-10.

Spalding, M.D., Ravilious, C., Green, E.P., 2001. World Atlas of Coral Reefs. University of California Press, Berkeley.

Tanaka, Y., Iguchi, A., Nishida, K., Inoue, M., Nakamura, T., Suzuki, A., Sakai, K., 2014. Nutrient availability affects the response of juvenile corals and the endosymbionts to ocean acidification. Limnol. Oceanogr. 59, 1468-1476.

Wenger, A.S., Johansen, J.L., Jones, G.P., 2012. Increasing suspended sediment reduces foraging, growth and condition of a planktivorous damselfish. J. Exp. Mar. Biol. Ecol. 428, 43-48.

Wenger, A.S., Fabricius, K.E., Jones, G.P., Brodie, J.E., 2015. Effects of Sedimentation, Eutrophication, and Chemical Pollution on Coral Reef Fishes. In: Mora, C. (Ed.), Ecology of Fishes on Coral Reefs. Cambridge University Press, Cambridge, pp. 145-153. 